\title{
Tarım topraklarının jeoistatistiksel modelleme ile kalitesinin değerlendirilmesi
}

\section{Evaluation of quality of agricultural soils with geostatistical modeling}

\author{
Yakup Kenan KOCA ${ }^{1 *}$, Mert ACAR ${ }^{2}$, Yavuz Şahin TURGUT ${ }^{2}$ iD \\ ${ }^{1}$ Dicle Üniversitesi, Ziraat Fakültesi, Toprak Bilimi ve Bitki Besleme Bölümü, Diyarbakır \\ ${ }^{2}$ Çukurova Üniversitesi, Ziraat Fakültesi, Toprak Bilimi ve Bitki Besleme Bölümü, Adana
}

\section{To cite this article:}

Koca, Y.K., Acar, M. \& Turgut, Y.Ş. (2019). Tarım topraklarının jeoistatistiksel modelleme ile kalitesinin değerlendirilmesi. Harran Tarım ve Gıda Bilimleri Dergisi, 23(4): 489-499.

DOI: 10.29050/harranziraat.556103

Address for Correspondence: Yakup Kenan KOCA e-mail:

ykkoca@dicle.edu.tr

Received Date:

19.04.2019

Accepted Date:

21.06.2019

(C) Copyright 2018 by Harran University Faculty of Agriculture. Available on-line at www.dergipark.gov.tr/harranziraat

\section{öz}

Tarımsal üretimde sürdürülebilirlik son yıllarda daha fazla önem verilen konulardan birisidir. Bu kapsamda toprakların mevcut durumunu bilmek ve uygun olmayan toprak özelliklerini belirlemek ve iyileştirmek en önemli adımdır. Mevcut duruma yapılacak her türlü etki kısa sürede kendini göstermese de uzun sürede olumlu veya olumsuz olarak toprak kalitesine yansıyacaktır. Bu sebeple, Türkiye'nin Çukurova Bölgesi sahil kesiminde yer alan Yumurtalık ilçe merkezi ve yakın çevresindeki toprakların verimlilik düzeyleri göz önünde bulundurularak toprak kalitesinin belirlenmesi ve dağılım haritasının oluşturulması amaçlanmıştır. Bu amaç için, daha önceden toprak etüdü yapılmış olan çalışma alanında rastgele belirlenen 110 noktaya ait toprakların $\mathrm{pH}$, elektriksel iletkenlik, kireç, katyon değişim kapasitesi, organik madde, kum, silt ve kil değerleri dikkate alınmıştır. Toprak kalite indeksi standart skorlama fonksiyonları ile skorlanan göstergelere analitik hiyerarşi süreci ile ağırlık verilerek belirlenmiştir. Çalışmada, yaklaşık 7694 ha arazinin toprak kalite sınıfları elde edilmiş ve jeoistatistiksel modelleme ile haritalanmıştır. Kalite düzeyleri bakımından beş sınıfta değerlendirilen topraklarda en fazla \%68.3 ile orta kaliteli topraklar belirlenmiştir. Buna karşın, çok düşük kaliteye sahip topraklar ise 82 ha ile çalışma alanının yalnızca \%1.1'inde yayılım göstermektedir. Çok yüksek kaliteli olarak tanımlanan topraklar ise çalışma alanında bulunmamaktadır. Çalışma alanında yer alan toprakların kalitesinin ilerleyen yıllarda tekrardan belirlenmesi ve zamanla meydana gelen değişimlerin ortaya çıkarılması, tarımda sürdürülebilirliğin sağlanması açısından oldukça önemlidir.

Anahtar Kelimeler: Verimlilik, Toprak kalitesi, Analitik hiyerarşi süreci, Standart skorlama fonksiyonu

\section{ABSTRACT}

Sustainability in agricultural production is one of the issues that are given more importance in recent years. In this context, to know the current situation of soils and to determine and improve the inappropriate soil properties are the most important step. Although any impact to the current situation doesn't appear in a short period, it will be reflected to the soil quality as positive or negative for a long time. For this reason, it is aimed to determine soil quality and spatial distribution map by considering the productivity levels of the soils in the Yumurtalık county center and its vicinity in the coastal area of Çukurova region, Turkey. $\mathrm{pH}$, electrical conductivity, lime, cation exchange capacity, organic matter, sand, silt and clay values of the soils for this purpose were taken into consideration as the productivity indicator of 110 points which were randomly determined in the study area which was previously surveyed. The soil quality index was determined by giving weight with analytic hierarchy process to scoring indicators with standard scoring functions. In this study, soil quality classes of approximately 7694 ha of land were obtained and mapped with geostatistical modeling. Soils with medium quality were determined with $68.3 \%$ at most in the soils evaluated in five classes in terms of quality levels. On the other hand, very low quality soils showed only $1.1 \%$ of the study area 
with 82 ha. Soils identified as very high quality weren't in the study area. The determination of the quality of the soils in the study area in the following years and revealing the changes taking place over time are very important in terms of ensuring sustainability in agriculture.

Key Words: Productivity, Soil quality, Analytic hierarchy process, Standard scoring function

\section{Giriş}

Artan dünya nüfusuna karşılık sınırlı genişlikteki tarım alanları insan beslenmesinde önemli bir tehdit oluşturmaktadır. Bu soruna yol açan sosyo-ekonomik faktörlerin yanı sıra toprak kaynaklarının bilinçsiz kullanımı, sorunun derecesini arttıran en önemli etmenlerden birisidir. İnsanlığın beslenme, giyinme, ısınma gibi ihtiyaçlarının büyük ölçüde toprağa bağımlı olduğu düşünüldüğünde, mevcut toprak kaynaklarının çok az bir kısmının tarımsal üretim için kullanılması, çözüm bulmakta zorlanılan beslenme sıkıntısının daha da artmasına yol açmaktadır. Başta ovalar olmak üzere, yüksek tarımsal potansiyele sahip alanlarda sürdürülebilir tarım daha fazla önem taşımaktadır (Bahçeci, 2014). Bu sıkıntıların hafifletilebilmesi veya giderilebilmesi için genişlemesi mümkün olmayan toprak kaynaklarının en uygun şekilde yönetimsel planlamalarının yapılarak sürdürülebilir bir şekilde kullanılması ve korunması, alınması gereken önlemlerin başında gelmektedir. Bunun içinde toprak kalitesinin belirlenmesi ve izlenmesi, amenajman kararlarına toprakların nasıl tepki verdiğini anlamak ve uygun yönetim tekniklerini seçmek için temel bir faktördür (Cherubin ve ark., 2016).

Toprak kalitesi "doğal veya yönetilen ekosistem içerisindeki bir toprağın bitkisel ve hayvansal üretimi sürdürebilme, su ve hava kalitesini artırabilme ve insan sağlığı için uygun yaşam ortamını oluşturma fonksiyonlarının tamamını sağlayabilme kapasitesi" olarak tanımlanmaktadır (Karlen ve ark., 1997). Fiziksel, kimyasal ve biyolojik özelliklerin bir bütünü olan toprak kalitesi toprak verimliliğinin en önemli göstergesidir. Yoğun üretim ve uygun olmayan toprak yönetim uygulamaları sonucunda, toprağın fiziksel, kimyasal ve biyolojik özellikleri olumsuz yönde etkilenmekte ve dolayısıyla toprak kalitesinin azalmasına neden olmaktadır (Bunemann ve ark., 2018; Bayman ve Turgut, 2018). Toprak kalitesinin azalması bir anlamda verimlilik düzeylerinin azalmasına ve ileri aşamada ise arazinin bozunumu anlamına gelmektedir. Toprak kalitesinin belirlenmesi ve belirli zamanlarda izlenmesi, tarımsal üretimde bozunmalar meydana gelmeden önce kullanılan amenajman tekniklerinin toprak verimliliği üzerindeki etkilerini değerlendirme imkanı tanıyacaktır.

Elverişli iklim ve sulama koşullarından dolayı bir yıl içerisinde iki ürün yetiştiriciliğinin yapıldığı Çukurova Bölgesi, Türkiye'nin en verimli bölgelerinden birisidir (Celik ve ark., 2012). Bu bölgede toprakların organik madde içeriklerinin düşük olmasının (Dinç ve ark., 1995) yanı sıra, geleneksel olarak çok sayıda işlenmesi ve anız artıklarının yasal olmayan bir şekilde yakılması (Celik ve ark., 2011), verimliliklerinin sürdürülebilirliğini engelleyen olumsuz durumların başında gelmektedir. Bu sebeple verimlilik hedefi doğrultusunda toprak kalitesinin mevcut durumunun belirlenmesi bölge topraklarında ortaya çıkması muhtemel sorunların öncesinde gerekli önlemler alınması açısından büyük bir öneme sahiptir.

Toprak kalitesinin değerlendirilmesinde bulunduğu çevre koşullarının etkilerini taşıyan, amenajman tekniklerine ve sürdürülebilirliğine göre farklı verim düzeylerine sahip olan toprakların, çevresel faktörlerle olan etkisinin değerlendirilebilmesi için skorlama işlemleri kullanılmaktadır (Karlen ve ark., 2001). Bu işlemler, doğrudan ölçülmesi mümkün olmayan toprak kalitesinin, doğru ve anlaşılabilir bir formatta değerlendirmesine olanak sağlamaktadır. Skorlama işlemi, birbirinden bağımsız olan toprak kalite göstergelerinin birimsiz kabul edilerek 0 ile 1 aralığında değerler alması (Liebig ve ark., 2001) ve toprak kalitesiyle 
doğrudan ilişkili ve yüksek etkileşim beklenilen parametrelerin pozitif, düşük etkileşimli ve dolaylı ilişki göstermesi beklenilenlerin ise negatif skorlama fonksiyonlarıyla gösterilmesine dayalı bir işlemdir (Armenise, 2013). Toprak kalitesini yansıtan indikatörlerin birimsiz oluşu ve her indikatörün birbirinden bağımsız değerlendirilmesi, toprak kalitesine hangi parametrenin ne derece etki ettiğinin kesin olarak bilinmemesine neden olur (Wymore, 1993). Bu sebeple son yıllarda, toprak kalitesini doğrudan ve dolaylı olarak etkileyen göstergelere ağırlık verilerek önemli indikatörleri belirlemek amacıyla analitik hiyerarşi süreci (AHS) ön plana çıkmıştır (Dengiz ve ark., 2015; Budak ve ark., 2018; Dengiz, 2019). Kısaca AHS "her bir karar alternatifini, karar vericinin kriterlerini yakalama derecesine göre sıralamak için rakamsal değerler geliştirme süreci” olarak tanımlanmaktadır (Saaty, 1987). AHS yöntemi, tanımlanmış tüm ilgili kriterlerin birbirleriyle tekrarlanabilir tercih faktörleri ile karşılaştırıldığı bir tercih matrisi yardımıyla, ağırlıklandırma faktörlerini hesaplamak için kullanılmaktadır (Mohammed ve Mohd, 2014). Böylece, toprak kalite parametrelerinin önem derecesine göre farklılık gösteren her bir faktörün etki değeri hesaplanabilmekte ve tanımlanabilmektedir.

Bu çalışmada Türkiye'nin güneyinde yer alan Çukurova Bölgesinde daha önceden Koca (2014) tarafından toprak etüdü yapılmış olan Yumurtalık ilçe merkezi ve yakın çevresinde bulunan toprakların verimlilik düzeyleri göz önünde bulundurularak standart skorlama fonksiyonu (SSF) ve analitik hiyerarşi süreci (AHS) yardımıyla uzman görüşüne göre kalitelerinin belirlenmesi ve model haritalarının oluşturulması amaçlanmıştır.

\section{Materyal ve Yöntem}

\section{Çalışma alanı}

Çalışma alanı Çukurova bölgesinde yer alan Adana ilinin sahil ilçelerinden biri olan Yumurtalık İlçesi ve yakın çevresini kapsamaktadır (Şekil 1). Çalışma alanı $36^{\circ} 48^{\prime} 38^{\prime \prime}$ ve $36^{\circ} 46^{\prime} 45^{\prime \prime}$ kuzey enlemleri ve $35^{\circ} 40^{\prime} 05^{\prime \prime}$ ve $35^{\circ} 49^{\prime} 12^{\prime \prime}$ doğu boylamları arasında yer almaktadır. Çalışma alanı yaklaşık 7694 ha olup, toplam alanın \%70'den fazlasını düz-düze yakın araziler oluşturmaktadır. Dik araziler ise çalışma alanının yalnızca \%1,97'sinde yer almaktadır. Çalışma alanında sahil kesimi hariç toprak derinliği açısından problem bulunmamaktadır. Çalışma alanı tipik Akdeniz ikliminden kısmen farklılıklar göstermektedir. Uzun yıllar iklimsel verileri değerlendirildiğinde, yıllık yağışın $797 \mathrm{~mm}$ ve yıllık ortalama sıcaklığın $18.8{ }^{\circ} \mathrm{C}$ olduğu görülmektedir (Anonim, 2019). Aylık iklimsel değerlere bakıldığında, en yağışı ayların Aralık ve Ocak ayları; en sıcak ayların ise Temmuz ve Ağustos ayları olduğu görülmektedir (Şekil 2). İlçenin en önemli geçim kaynağı balıkçılıktır. Çalışma alanının çok önemli bir kısmında tarımsal faaliyet yürütülmektedir. Tarımsal ürünler içerisinde buğday, ayçiçeği, mısır, soya, pamuk ve karpuz ön plana çıkmaktadır. Çalışma alanı dışında tutulan arazilerde ise Yumurtalık ilçe merkezi ve yazlık olarak kullanılan binalar yer almaktadır.

\section{Çalışma alanı toprakları}

Çalışma alanında birbirinden çok farklı toprak serileri bulunmaktadır. Bu seriler Kalemli, Yellibelen, Ayvalık, İkisu Deresi, Herekli, Söğütçe, Yeniköy, Çorak Deresi, Tebeşirlik, Koyaklı, Duranağa, Çeşme Deresi, Zeytinbeli, Keltepe, Küçük Yumurtalık, Yumurtalık ve Fettah Plajı serileri olarak tanımlanmıştır. $\mathrm{Bu}$ serilerden Kalemli, Yellibelen, Ayvalık, i̇kisu Deresi, Herekli ve Söğütçe serileri koluviyal ana materyal üzerinde oluşurken, Çorak Deresi serisi aluviyal ana materyal üzerinde oluşmuştur.

Bununla birlikte Tebeşirlik, Koyaklı ve Duranağa serileri marn ana materyali; Çeşme Deresi, Zeytinbeli ve Keltepe serileri kumtaşı ana materyali; Küçük Yumurtalık serisi kiltaşı ana materyali; Yumurtalık ve Fettah Plajı serileri ise kıyı kumulları ana materyali üzerinde yer almaktadır. Çalışma alanında yer alan bu serilerin Toprak Taksonomisine göre sınıflandırılması Koca (2014) tarafından yapılmış ve Çizelge 1'de verilmiştir. 


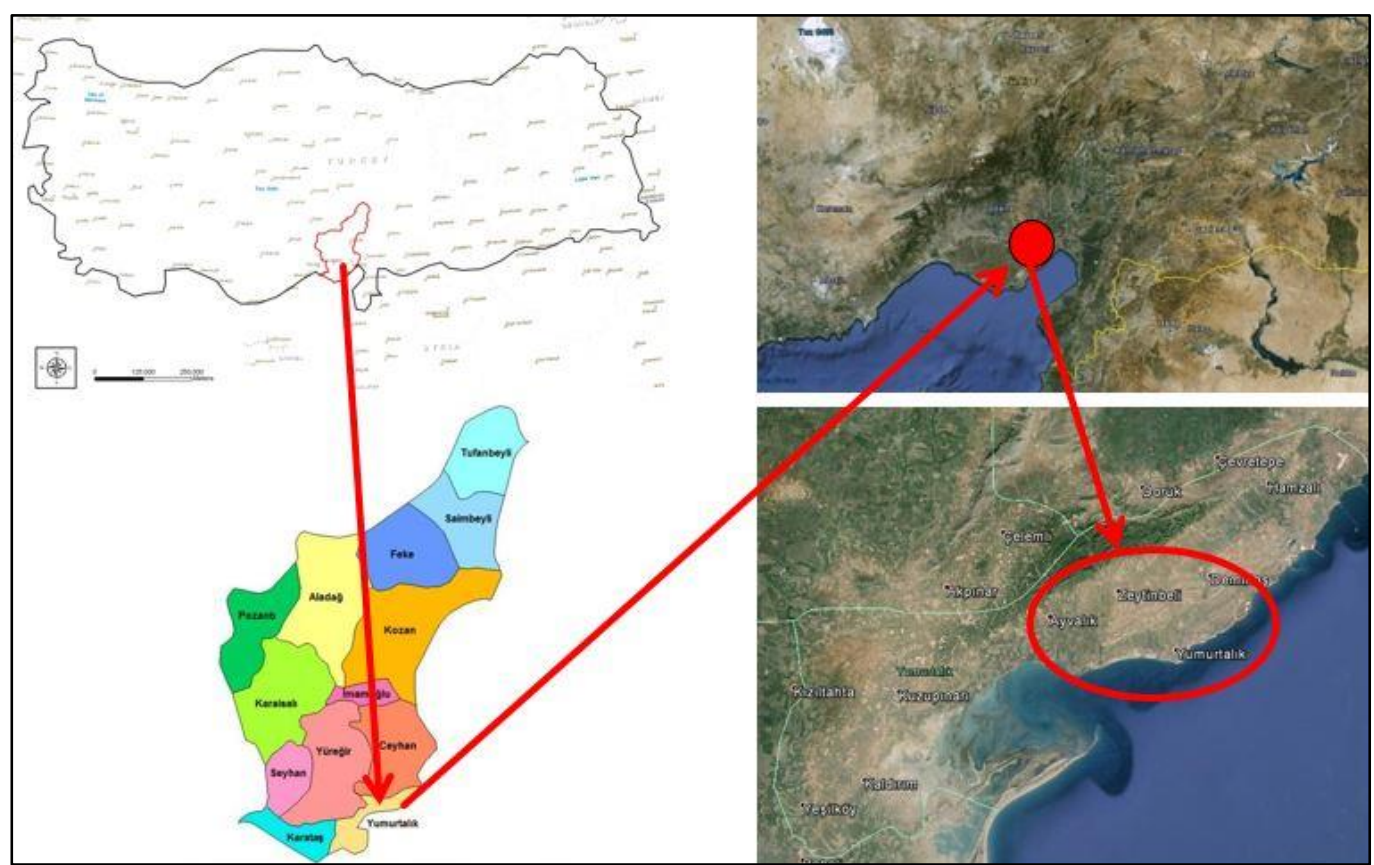

Şekil 1. Çalışma alanı coğrafi konumu

Figure 1. Geographic location of study area

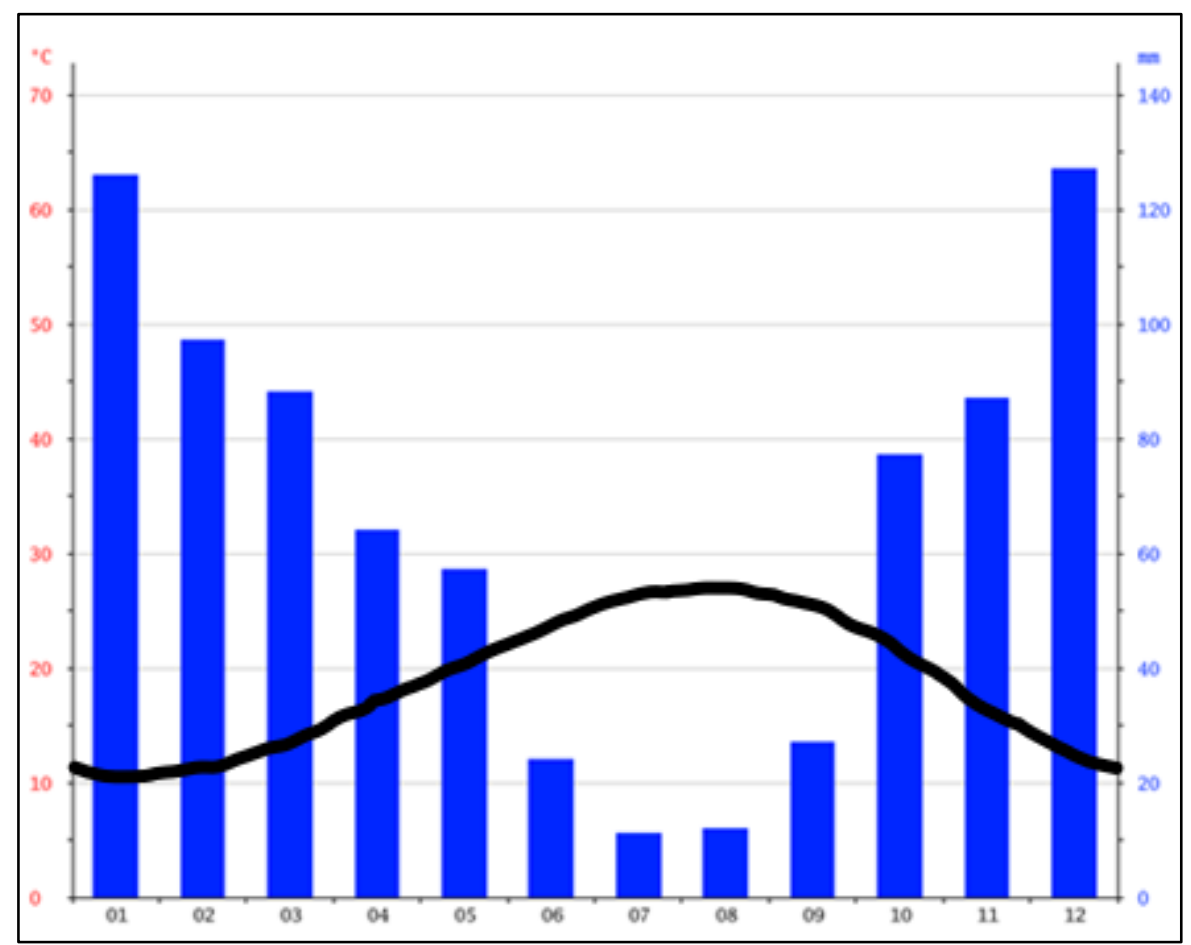

Şekil 2. Yumurtalık ilçesi iklim verileri (Anonim, 2019)

Figure 2. Climate data of Yumurtalık county

Tüm serilerden alanın tamamını temsil edecek şekilde 110 adet nokta belirlenmiş ve bu noktalara tesadüfi gelen serilerin toprak özellikleri ArcGIS 10.2 yazılıma veritabanı şeklinde girilmiştir. Bu kapsamda serilerin yüzey horizonlarına ait daha önceden Koca ve Şenol (2018) tarafından analizleri yapılmış olan toprakların $\mathrm{pH}$, elektriksel iletkenlik (EC), kireç, katyon değişim kapasitesi (KDK), organik madde, kum, silt ve kil gibi fiziksel ve kimyasal özellikleri değerlendirilmiştir. Söz konusu çalışmada, pH ve EC, 1:2.5'luk toprak-su karışımında belirlenmiştir (U.S. Salinity Laboratory Staff, 1954). Toprakların kireç içeriği Schiebler kalsimetresi ile (Schlichting and Blume, 1966), KDK sodyum asetat metodu ile (U.S. Salinity Laboratory Staff, 1954), organik madde içeriği Walkley-Black yöntemi ile (Allison, 1965) belirlenmiştir. Toprak tekstürü ise Bouyoucus (1951)'a göre hidrometre yöntemi ile belirlenmiştir. 
Çizelge 1. Çalışma alanında tanımlanan toprak serisi ve toprak ordolarının alansal ve oransal dağılımları Table 1. Spatial and proportional distributions of soil series and soil ordo defined in study area

\begin{tabular}{|c|c|c|c|c|c|}
\hline \multirow{2}{*}{$\begin{array}{c}\text { Toprak Serisi } \\
\text { Soil Series }\end{array}$} & \multicolumn{2}{|c|}{$\begin{array}{c}\text { Dağılım } \\
\text { Distribution }\end{array}$} & \multirow{2}{*}{$\begin{array}{l}\text { Toprak Ordosu } \\
\text { Soil Ordo }\end{array}$} & \multicolumn{2}{|c|}{$\begin{array}{c}\text { Dağılım } \\
\text { Distribution }\end{array}$} \\
\hline & ha & $\%$ & & ha & $\%$ \\
\hline Herekli & 1266 & 16.45 & \multirow{13}{*}{ Entisol } & \multirow{13}{*}{5819} & \multirow{13}{*}{75.62} \\
\hline Tebeşirlik & 910 & 11.83 & & & \\
\hline Keltepe & 880 & 11.44 & & & \\
\hline Küçük Yumurtalık & 673 & 8.75 & & & \\
\hline Ayvalık & 638 & 8.29 & & & \\
\hline Yellibelen & 469 & 6.10 & & & \\
\hline Çeşme Deresi & 298 & 3.87 & & & \\
\hline Koyaklı & 241 & 3.13 & & & \\
\hline Çorak Deresi & 148 & 1.92 & & & \\
\hline Kalemli & 94 & 1.22 & & & \\
\hline Fettah Plajı & 87 & 1.13 & & & \\
\hline Yumurtalık & 65 & 0.84 & & & \\
\hline Söğütçe & 50 & 0.65 & & & \\
\hline Yeniköy & 1090 & 14.17 & \multirow{2}{*}{ Vertisol } & \multirow{2}{*}{1651} & \multirow{2}{*}{21.46} \\
\hline İkisu Deresi & 561 & 7.29 & & & \\
\hline Duranağa & 84 & 1.09 & \multirow{2}{*}{ İnceptisol } & \multirow{2}{*}{107} & \multirow{2}{*}{1.39} \\
\hline Zeytinbeli & 23 & 0.30 & & & \\
\hline Diğer & 118 & 1.53 & Diğer & 118 & 1.53 \\
\hline Toplam & 7694 & 100.00 & Toplam & 7694 & 100.00 \\
\hline
\end{tabular}

Göstergelerin skorlanması, ağırlıklandırılması ve toprak kalitesi

Toprak kalite göstergeleri standart skorlama fonksiyonları kullanılarak birbiri ile kıyaslanabilir olması ve verimlilik açısından toprak kalitesinin belirlenmesi için 0.1 ile 1.0 arasında birimsiz skorlara dönüştürülmüştür (Çizelge 2). Literatürde genel olarak "daha fazla daha iyidir", "daha az daha iyidir" ve "orta nokta optimumdur" olmak üzere 3 adet skorlama fonksiyonu bulunmaktadır (Karlen ve Stott., 1994; Masto ve ark., 2008; Liu ve ark., 2018). "Daha fazla daha iyidir" ile skorlamada, göstergenin yüksek skor elde etmesi, toprak kalitesi ile arasında pozitif ilişki olduğunu göstermektedir. "Daha az daha iyidir" ile skorlamada, göstergenin düşük skor elde etmesi, toprak kalitesi ile arasında negatif bir ilişki olduğunu göstermektedir. "Orta nokta optimumdur" ile skorlamada ise bazı göstergeler için eşik değerleri belirlenip, bu eşik değerin üstünde veya altında olup olmadığına göre göstergeler "daha fazla daha iyidir" ve "daha az daha iyidir" ile birimsiz hale dönüştürülmektedir. Bu çalışmada "daha fazla daha iyidir" ile KDK, organik madde ve kil değerleri skorlanırken, "daha az daha iyidir" ile EC, kireç, silt ve kum değerleri skorlanmıştır. Literatürde $\mathrm{pH}$ skorlanırken "orta nokta optimumdur" eğrisinin kullanımı tercih edilmektedir (Andrews ve ark., 2004). Verimlilik açısından toprak kalitesinin belirlenmesinde bitki gelişimi için en çok arzu edilen pH sınırları 6.0 ile 7.0 arasıdır (Marschner, 2011). Çalışmada elde edilen $\mathrm{pH}$ değerlerinin $>7$ olması, bu göstergenin "daha az daha iyidir" ile skorlanmasına sebep olmuştur. 
Çizelge 2. Toprak kalite göstergelerine ait standart skorlama fonksiyonları

Table 2. Standard scroring functions of soil quality indicators

\begin{tabular}{|c|c|c|c|c|c|c|}
\hline $\begin{array}{l}\text { Gösterge } \\
\text { Indicator }\end{array}$ & $\begin{array}{l}\text { Skorlama } \\
\text { Scoring }\end{array}$ & $\mathrm{L}$ & U & & $\begin{array}{r}\text { Standart Skorlama } \\
\text { Standard Scoring }\end{array}$ & $\begin{array}{l}\text { Fonksiyonu } \\
\text { Functions }\end{array}$ \\
\hline $\mathrm{pH}$ & \multirow{5}{*}{ Daha az daha iyidir } & 7.2 & 7.9 & \multirow{5}{*}{$f(x)=$} & \multirow{5}{*}{$\begin{array}{c}1 \\
1-0.9 x \frac{x-L}{U-L} \\
0.1\end{array}$} & \multirow{5}{*}{$\begin{array}{c}x \leq L \\
L \leq x \leq U \\
x \geq U\end{array}$} \\
\hline $\mathrm{EC}, \mathrm{mmhos}$ & & 0.1 & 0.4 & & & \\
\hline $\begin{array}{l}\text { Kireç, \% } \\
\text { Lime, \% }\end{array}$ & & 5.7 & 60.2 & & & \\
\hline Silt, \% & & 3.8 & 45.4 & & & \\
\hline $\begin{array}{l}\text { Kum, \% } \\
\text { Sand, \% }\end{array}$ & & 23.3 & 89.0 & & & \\
\hline $\begin{array}{l}\mathrm{KDK}, \mathrm{me} / 100 \mathrm{~g} \\
\mathrm{CEC}, \mathrm{me} / 100 \mathrm{~g}\end{array}$ & \multirow{3}{*}{ Daha fazla daha iyidir } & 13.6 & 41.7 & \multirow{3}{*}{$f(x)=$} & \multirow{3}{*}{$0.9 \times \frac{x-L}{U-L}+0.1$} & \multirow{3}{*}{$\begin{array}{c}x \leq L \\
L \leq x \leq U \\
x \geq U\end{array}$} \\
\hline $\begin{array}{l}\text { Organik madde, \% } \\
\text { Organic matter, \% }\end{array}$ & & 1.2 & 2.3 & & & \\
\hline $\begin{array}{l}\text { Kil, \% } \\
\text { Clay, \% }\end{array}$ & & 7.1 & 55.3 & & & \\
\hline
\end{tabular}

EC: Elektriksel iletkenlik, KDK: Katyon değişim kapasitesi, L: Minimum değer, U: Maksimum değer, x: Ölçülen değer

EC: Electrical conductiviy, CEC: Cation Exchange capacity, L: Minimum value, U: Maximum value, x: Measured value

Birimsiz skorlara dönüştürülen toprak kalite göstergelerinin hangisinin ne derecede önemli olduğunu vurgulamaya yarayan ve Saaty (1980) tarafından geliştirilen AHS ile göstergelere ağırlık verilmiştir. Ağırlıklandırılmış toprak göstergelerinin verimlilik hedefi doğrultusunda bir toprak kalite indeksi altında birleştirilmesinde aşağıdaki eşitlik kullanılmış ve sonuçlar yüzde olarak hesaplanmıştır.

$$
T K \dot{\mathrm{I}}_{\text {verimlilik }}=\left(\sum_{i=0}^{n} W_{i} x S_{i}\right) * 100
$$

Burada TKi: Toprak kalite indeksini, Wi: göstergelerin AHS ile verilmiş ağırlıkları, Si: gösterge skorunu ve $\mathrm{n}$ : gösterge sayısını ifade etmektedir. Elde edilen toprak kalite indeksleri Gugino ve ark. (2009) tarafından belirtilen verimlilik skorlarına göre sınıflandırılmış ve haritalanmıştır (Çizelge 3).

Çizelge 3. Toprak kalitesinin sınıflandırılması Table 3. Classification of soil quality

\begin{tabular}{|l|c|}
\hline $\begin{array}{l}\text { Skor } \\
\text { Score }\end{array}$ & $\begin{array}{c}\text { Tanımlama } \\
\text { Description }\end{array}$ \\
\hline$>85$ & $\begin{array}{c}\text { Çok yüksek } \\
\text { Very high }\end{array}$ \\
\hline $70-85$ & $\begin{array}{c}\text { Yüksek } \\
\text { High }\end{array}$ \\
\hline $55-70$ & $\begin{array}{c}\text { Orta } \\
\text { Medium } \\
\text { Düşük } \\
\text { Low }\end{array}$ \\
\hline $40-55$ & $\begin{array}{c}\text { Çok düşük } \\
\text { Very low }\end{array}$ \\
\hline$<40$ & \\
\hline
\end{tabular}

\section{Toprak kalitesinin jeoistatistiksel haritalanması}

Elde edilen toprak kalite skorları ArcGIS 10.2 ortamında point (nokta) olarak belirlenen alanlara ait veri tabanına girilmiştir. Bu kapsamda çalışma alanı topraklarının kalite indekslerinin hesaplanması, alan içerisindeki toprakların özelliklerinin jeoistatistiksel modelleme yardımıyla tüm alana yayılması ve alan içerisinde bu indekslerin dağılımının belirlenmesi amacıyla ArcGIS 10.2 enterpolasyon modelleri kullanılmıştır. Enterpolasyon modelleri içinde RMSE değeri en düşük olan metot, en uygun metot olarak değerlendirilmiş ve haritaları oluşturulmuştur. Bu kapsamda ele alınan jeoistatistiksel modelleme yöntemlerinden en uygun metod olarak hata değerleri en düşük olan spherical model kullanılarak ordinary kriging ile değerlendirilmiş ve toprak kalite haritası bu metoda göre oluşturulmuştur.

\section{Araştırma Bulguları ve Tartışma}

\section{Serilerin toprak kalitesi skorları}

Çalışma alanında bulunan topraklar standart skorlama fonksiyonları ile skorlanmış ve Çizelge 4'te yer alan ağırlıklar kullanılarak uzman görüşüne göre ağırlıklandırılmıştır. Organik madde 0.27 ile en yüksek ağırlığı alırken, bunu 0.21 ağırlığı ile $\mathrm{pH}$ izlemiştir. Çalışmada en düşük ağırlık (0.04) ise silt göstergesine verilmiştir. Bu durum 
verimlilik açısından toprak kalitesinin değerlendirilmesinde toprak kalitesinin en önemli göstergelerinden biri olarak kabul edilen organik maddeyi (Andrews ve ark., 2004) ön plana çıkarmaktadır.

Çizelge 4. Toprak kalite göstergelerine ait AHS ile verilen ağırlıklar

Table 4. Weights with AHP of soil quality indicators

\begin{tabular}{|l|c|}
\hline $\begin{array}{l}\text { Göstergeler } \\
\text { Indicators }\end{array}$ & $\begin{array}{c}\text { Ağırlık } \\
\text { Weight }\end{array}$ \\
\hline $\mathrm{pH}$ & 0.21 \\
\hline $\begin{array}{l}\text { Elektriksel iletkenlik } \\
\text { Electrical conductivity }\end{array}$ & 0.06 \\
\hline $\begin{array}{l}\text { Kireç } \\
\text { Lime }\end{array}$ & 0.08 \\
\hline $\begin{array}{l}\text { Katyon değişim kapasitesi } \\
\text { Cation exchange capacity }\end{array}$ & 0.12 \\
\hline $\begin{array}{l}\text { Organik madde } \\
\text { Organic matter }\end{array}$ & 0.27 \\
\hline $\begin{array}{l}\text { Kil } \\
\text { Clay }\end{array}$ & 0.14 \\
\hline Silt & 0.04 \\
\hline $\begin{array}{l}\text { Kum } \\
\text { Sand }\end{array}$ & 0.09 \\
\hline $\begin{array}{l}\text { Toplam } \\
\text { Total }\end{array}$ & 1.00 \\
\hline
\end{tabular}

Toprak kalitesi ve verimlilik göstergelerine ait tanımlayıcı istatistik sonuçları Çizelge 5'te verilmiştir. En düşük toprak kalitesi skoru \%35.5 ile Yumurtalık Serisinde belirlenmiş olup çok düşük olarak sınıflandırımıştır. En yüksek toprak kalitesi skoru ise \%80.3 ile Zeytinbeli serisinde bulunmuş olup yüksek olarak tanımlanmıştır. Çalışma alanında yer alan tüm seriler arasında toprak kalitesi bakımından çok yüksek olarak tanımlanan herhangi bir seri bulunmazken Ayvalık, íkisu Deresi, Yeniköy, Duranağa ve Keltepe yüksek olarak tanımlanan diğer serilerdir. Orta düzeyde toprak kalitesi skoruna sahip seriler ise Kalemli, Çorak Deresi, Tebeşirlik, Koyaklı, Çeşme Deresi, Küçük Yumurtalık ve Fettah Plajı serileridir. Yellibelen, Herekli ve Söğütçe serileri ise toprak verimliliği açısından düşük kalitede olarak tanımlanmıştır. Yumurtalık serisinde toprak kalitesinin düşük çıkmasının sebebi kil, silt, kum ve KDK göstergelerine ait ağırlıklandırılmış skorlarının düşük değerler almasından kaynaklanmaktadır. Buna karşın Zeytinbeli serisinde bütün göstergeler dikkate alındığında yüksek ağırlıklandırımış skorlar alması toprak kalitesinin en yüksek çıkmasına sebep olmuştur.

Çizelge 5. Toprak serilerinin kalite göstergelerine ait ağılıklandırılmış skor değerleri

Table 5. Weighted scoring values of soil quality index of soil series

\begin{tabular}{|l|c|c|c|c|c|c|c|c|c|}
\hline $\begin{array}{l}\text { Seri Adı } \\
\text { Series Name }\end{array}$ & $\mathrm{pH}$ & $\mathrm{EC}$ & $\begin{array}{c}\text { KDK } \\
\text { CEC }\end{array}$ & $\begin{array}{c}\text { Kireç } \\
\text { Lime }\end{array}$ & OM & $\begin{array}{c}\text { Kil } \\
\text { Clay }\end{array}$ & $\begin{array}{c}\text { Silt } \\
\text { Kum } \\
\text { Kalemli }\end{array}$ Sand & $\begin{array}{c}\text { TK (\%) } \\
\text { SQ }\end{array}$ \\
\hline Yellibelen & 0.16 & 0.02 & 0.04 & 0.06 & 0.13 & 0.12 & 0.03 & 0.09 & 62.7 \\
\hline Ayvalık & 0.17 & 0.02 & 0.08 & 0.05 & 0.25 & 0.08 & 0.03 & 0.08 & 75.8 \\
\hline İkisu deresi & 0.08 & 0.04 & 0.10 & 0.07 & 0.20 & 0.14 & 0.02 & 0.08 & 73.5 \\
\hline Herekli & 0.13 & 0.05 & 0.08 & 0.04 & 0.05 & 0.07 & 0.03 & 0.08 & 52.7 \\
\hline Söğütçe & 0.20 & 0.06 & 0.07 & 0.07 & 0.05 & 0.02 & 0.03 & 0.05 & 54.7 \\
\hline Yeniköy & 0.18 & 0.04 & 0.11 & 0.05 & 0.20 & 0.12 & 0.02 & 0.08 & 80.1 \\
\hline Çorak Deresi & 0.09 & 0.03 & 0.04 & 0.05 & 0.22 & 0.07 & 0.03 & 0.07 & 59.8 \\
\hline Tebeşirlik & 0.14 & 0.03 & 0.05 & 0.01 & 0.23 & 0.05 & 0.03 & 0.07 & 61.9 \\
\hline Koyaklı & 0.17 & 0.04 & 0.04 & 0.01 & 0.14 & 0.07 & 0.04 & 0.08 & 58.2 \\
\hline Duranağa & 0.08 & 0.03 & 0.12 & 0.08 & 0.19 & 0.13 & 0.02 & 0.08 & 73.3 \\
\hline Çeşme Deresi & 0.18 & 0.05 & 0.08 & 0.05 & 0.06 & 0.07 & 0.02 & 0.06 & 56.3 \\
\hline Zeytinbeli & 0.20 & 0.05 & 0.10 & 0.05 & 0.21 & 0.09 & 0.03 & 0.08 & 80.3 \\
\hline Keltepe & 0.15 & 0.02 & 0.05 & 0.06 & 0.27 & 0.06 & 0.04 & 0.08 & 72.3 \\
\hline Küçük Yumurtalık & 0.15 & 0.01 & 0.08 & 0.06 & 0.06 & 0.11 & 0.03 & 0.09 & 57.5 \\
\hline Yumurtalık & 0.21 & 0.04 & 0.01 & 0.05 & 0.03 & 0.01 & 0.00 & 0.01 & 35.5 \\
\hline Fettah Plajı & 0.18 & 0.03 & 0.06 & 0.06 & 0.12 & 0.06 & 0.03 & 0.06 & 59.3 \\
\hline
\end{tabular}

EC: Elektriksel iletkenlik, KDK: Katyon değişim kapasitesi, OM: Organik madde, TK: Toprak kalitesi

EC: Electrical conductivity, CEC: Cation exchange capacity, OM: Organic matter, SQ: Soil quality 
Ağırlıklandırılmış toprak kalite göstergeleri ve toprak kalitesine ait tanımlayıcı istatistikler Çizelge $6^{\prime}$ da verilmiştir. Camberdella ve ark. (1994), arazideki değişkenliğin ifadesinde kullanılan varyasyon katsayısını (VK), <\%15 olanlar az değişken, \%16-35 arasında olanlar orta derecede değişken ve >\%36 olanlar ise yüksek derecede değişken olarak gruplandırmıştır. Buna göre çalışma alanında ağırlıklandırımıs silt ve kum skorları orta derecede değişken iken, diğer ağırlıklandırımış $\mathrm{pH}, \mathrm{EC}$, kireç, KDK ve organik madde skorları çok değişken olarak tanımlanmıştır. Ağırlıklandırılmış bireysel göstergelerden elde edilen toprak kalitesi ise en düşük VK (\%18.8)'ya sahip olarak orta derecede değişken sınıfında yer almıştır. Çalışma alanında uygulanan farklı amenajman teknikleri ve farklı genetik özelliklerden dolayı ölçülen özelliklerin yüksek varyasyon katsayısı almasına sebep olmuştur.

Çizelge 6. Toprak serilerinin ağırlıklandırılmış toprak kalite göstergeleri ve toprak kalitesine ait tanımlayıcı istatistikler

Table 6. Descriptive statistics of weighted soil quality indicator and soil quality of soil series

\begin{tabular}{|l|c|c|c|c|c|c|}
\hline $\mathrm{n}=17$ & $\begin{array}{c}\text { En küçük değer } \\
\text { Minimum value }\end{array}$ & $\begin{array}{c}\text { En yüksek değer } \\
\text { Maximum value }\end{array}$ & $\begin{array}{c}\text { Ortalama } \\
\text { Average }\end{array}$ & $\begin{array}{c}\text { Standart Sapma } \\
\text { Standard Deviation }\end{array}$ & $\begin{array}{c}\text { VK (\%) } \\
\text { CV }\end{array}$ & $\begin{array}{c}\text { Yatıklık } \\
\text { Skewness }\end{array}$ \\
\hline $\mathrm{pH}$ & 0.02 & 0.21 & 0.15 & 0.05 & 35.7 & -1.04 \\
\hline $\mathrm{EC}$ & 0.01 & 0.06 & 0.03 & 0.01 & 44.9 & -0.25 \\
\hline $\begin{array}{l}\text { Kireç } \\
\text { Lime }\end{array}$ & 0.01 & 0.08 & 0.05 & 0.02 & -0.89 \\
\hline $\begin{array}{l}\text { KDK } \\
\text { CEC }\end{array}$ & 0.01 & 0.12 & 0.07 & 0.03 & 41.8 & -0.10 \\
\hline OM & 0.03 & 0.27 & 0.15 & 0.08 & 52.1 & -0.23 \\
\hline $\begin{array}{l}\text { Kil } \\
\text { Clay }\end{array}$ & 0.01 & 0.14 & 0.08 & 0.03 & 43.6 & 0.03 \\
\hline Silt & 0.00 & 0.04 & 0.03 & 0.01 & 32.3 & -1.21 \\
\hline $\begin{array}{l}\text { Kum } \\
\text { Sand }\end{array}$ & 0.01 & 0.09 & 0.07 & 0.02 & 27.9 & -2.25 \\
\hline $\begin{array}{l}\text { TK } \\
\text { SQ }\end{array}$ & 35.5 & 80.3 & 62.7 & 11.77 & 18.8 & -0.31 \\
\hline
\end{tabular}

EC: Elektriksel iletkenlik, KDK: Katyon değişim kapasitesi, OM: Organik madde, TK: Toprak kalitesi, VK: Varyasyon katsayıSı EC: Electrical conductivity, CEC: Cation exchange capacity, OM: Organic matter, SQ: Soil quality, CV: Coefficient of variation

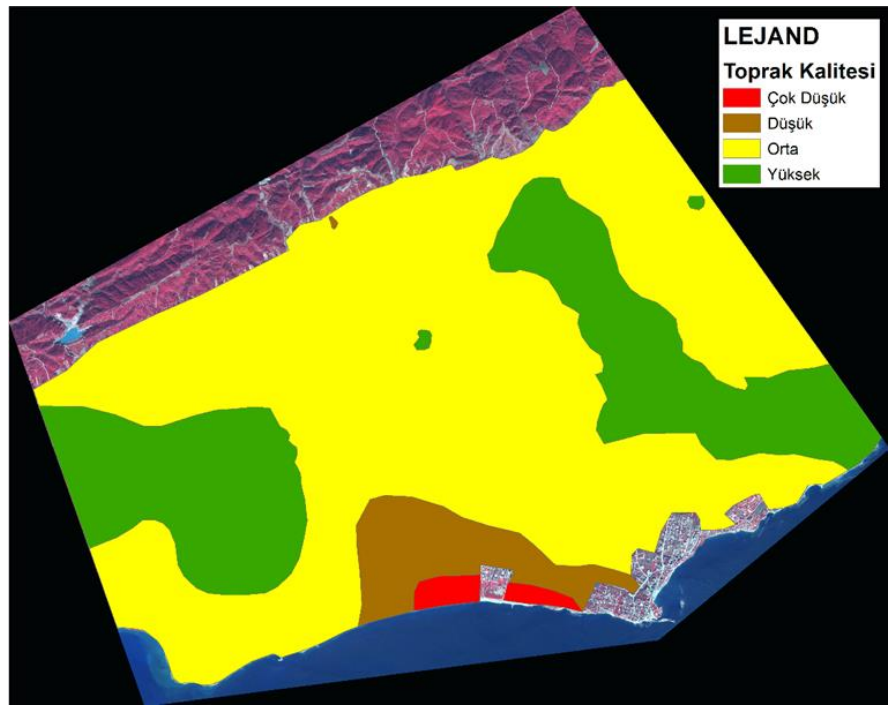

Şekil 3. Çalışma alanının toprak kalitesi modelleme haritası Figure 3. Soil quality modeling map of study area

Çalışma alanı topraklarına ait kalite haritası değerlendirildiğinde, en düşük kaliteye sahip toprakların Yumurtalık ilçe merkezi yakın çevresinde yer alan Yumurtalık serisinin yayılım gösterdiği alanlarda olduğu görülmektedir. Düşük toprak kalitesine sahip topraklar ise Yumurtalık ilçe merkezi ile Kalemli beldesi arasında kalan bölgede görülmektedir. Çalışma alanında en fazla yer kaplayan orta düzeyde toprak kalitesine sahip araziler ise, çalışma alanının kuzey ve orta kesimlerinde özellikle Zeytinbeli beldesi ve çevresinde geniş alanlarda yayılım göstermektedir. Yüksek toprak kalitesine sahip araziler ise batıda Ayvalık beldesi ve yakın çevresinde, doğu tarafında ise Demirtaş ve yakın çevresinde dağılım gösterdiği görülmektedir. Genel olarak toprak kalite haritasına bakıldığında sahile yakın kesimlerde ve yüksek düzeyde kumlu bünyeye sahip arazilerde düşük-çok düşük toprak kalitesine sahip olduğu görülürken; sahilden uzaklaştıkça toprak kalitesinin yükseldiği görülmektedir. Bu şekilde dağılım görülmesinin en 
büyük nedeni, kaliteyi etkileyen önemli toprak özelliklerinden birisinin de toprakların sahip olduğu kum yüzdesidir. Nitekim çalışma alanı içerisinde en yüksek kum yüzdesine sahip olan Yumurtalık serisinin en düşük toprak kalite skoruna sahip olması da bu sebepten ileri gelmektedir.

Çalışma alanında toprak kalitesi genel olarak \%35.5 ile \%80.3 arasında değişmekte olup, verimliliği çok yüksek topraklar çalışma alanında tanımlanamamıştır. Bunun dışında dağııım haritasına göre çalışma alanında 5253 ha ile en fazla orta kaliteye sahip topraklar bulunmaktadır (Şekil 3 ve Çizelge 7). Bu sınıf topraklar çalışma alanının yaklaşık \%68.3'ünü oluşturmaktadır. Yüksek kaliteye sahip topraklar ise çalışma alanında 1932 ha olup, toplam çalışma alanının \%25.1'inde dağılım göstermektedir. Verimliliğin düşük olarak nitelendirildiği düşük toprak kalitesine sahip alanlar ise çalışma alanında 427 ha alanda dağılım göstermekte olup toplam çalışma alanının yaklaşık \%5.6'sına denk gelmektedir. Çalışma alanında en az yer kaplayan çok düşük kaliteye sahip topraklar ise \%1.1 ile sadece 82 ha alanda dağılım göstermektedirler.

Çizelge 7. Çalışma alanı topraklarının kalite düzeyleri

Table 7. Soil quality levels of study area soils

\begin{tabular}{|l|c|c|}
\hline \multirow{2}{*}{$\begin{array}{l}\text { Tanımlama } \\
\text { Description }\end{array}$} & \multicolumn{2}{|c|}{\begin{tabular}{c} 
Alan \\
\cline { 2 - 3 }
\end{tabular}} \\
$\begin{array}{l}\text { Çok düşük } \\
\text { Very low }\end{array}$ & 82 & 1.1 \\
\hline $\begin{array}{l}\text { Düşük } \\
\text { Low }\end{array}$ & 427 & 5.5 \\
\hline $\begin{array}{l}\text { Orta } \\
\text { Medium }\end{array}$ & 5253 & 68.3 \\
\hline $\begin{array}{l}\text { Yüksek } \\
\text { High }\end{array}$ & 1932 & 25.1 \\
\hline $\begin{array}{l}\text { Toplam } \\
\text { Total }\end{array}$ & 7694 & 100.0 \\
\hline
\end{tabular}

\section{Sonuçlar}

Mevcut fiziksel ve kimyasal özelliklerden yola çıkılarak belirlenen toprak kalitesi, verimliliğin önemli bir göstergesi olarak kabul edilmektedir. Son yıllarda toprakların yoğun kullanımı ve uygun olmayan amenajman uygulamaları sonucu toprakların fiziksel ve/veya kimyasal özelliklerinde bozulmalar meydana getirmektedir ki bu durum sürdürülebilir tarım açısından önemli bir sorun olarak karşımıza çıkmaktadır. Bu çalışmada Adana ili Yumurtalık ilçesi ve yakın çevresinde bulunan yaklaşık 7694 ha arazideki toprakların toprak kalitesi düzeyi ortaya konulmaya çalışılmıştır. Daha önceden tanımlanmış olan farklı seri ve noktalardan rastgele belirlenen 110 noktaya ait $\mathrm{pH}, \mathrm{EC}$, kireç, KDK, organik madde, kum, silt ve kil değerleri değerlendirilmiş, toprak kalite göstergeleri standart skorlama fonksiyonları kullanılarak birbiri ile kıyaslanabilir olması ve verimlilik açısından toprak kalitesinin belirlenmesi için 0.1 ile 1.0 arasında birimsiz skorlara dönüştürülmüş ve AHS ile ağırlıklandırılarak toprakların kalitesi değerlendirilmiştir. Bu kapsamda çalışma alanındaki toprakların kalite skorları \%35.5 ile \%80.3 arasında değiştiği gözlenmiştir. En düşük skora sahip seri Yumurtalık; en yüksek skora sahip seri ise Zeytinbeli serisi olarak tanımlanmıştır.

Elde edilen noktasal verilerden yola çıkarak jeoistatistiksel modelleme ile tüm çalışma alanına ait toprak kalitesi haritası elde edilmiştir. Bu aşamada çeşitli modeller uygulanmış ve en uygun model olarak Ordinary Kriging metodundan elde edilmiş ve haritalanmıştır. Elde edilen model haritaları ve alansal veriler, çalışma alanı topraklarının genellikle orta ve yüksek kalite düzeylerine sahip topraklar olduğunu göstermiştir. Çok düşük toprak kalitesine sahip topraklar ise çalışma alanında çok küçük bir yer kaplamaktadır. Çok düşük toprak kalite skoruna sahip tek seri olan Yumurtalık seri toprakları özellikle Yumurtalık illçe merkezi ve yakın çevresinde sahil olarak adlandırılabilecek denize yakın bölgelerde yer almaktadır. Bu serinin sahip olduğu en önemli dezavantaj yüksek kum içeriğine sahip olmasından kaynaklanmaktadır. Düşük toprak kalitesine sahip alanlar ise genellikle Yumurtalık serisi ile çalışma alanının kuzeyi arasında kalan geçiş bölgesinde yer alan topraklardır. Orta düzeyde toprak kalitesine sahip alanlar ise çalışma alanında oldukça geniş yer kaplamakta olup, çalışma alanının orta ve kuzey kesimlerinde önemli düzeyde dağılım 
göstermektedir. Çalışma alanında bulunan toprakların ağırlıklandırılmış skorlarının değerlendirilmesi neticesinde çalışma alanında çok yüksek toprak kalitesine sahip seri bulunmamıştır.

$\mathrm{Bu}$ çalışmada kullanılan toprak kalitesi skorlamaları serilerin yüzey horizonlarının kimi özelliklerine göre elde edilmiştir. Bu kapsamda yapılması gereken çalışmalardan birisi de toprak kalitesinde zamansal değişimleri ortaya çıkartmaktır. Mevcut durumda meydana gelebilecek küçük değişimler olumlu ya da olumsuz toprak kalitesine etkide bulunabilmektedir. Bundan dolayı toprak kalitesinin sürekli olarak izlenmesi tarımsal ve çevresel yönden iyi uygulamaların seçiminde yardımcı olması açısından önem arz etmektedir.

\section{Kaynaklar}

Allison, L. E. (1965). Organic Carbon. In: Methods of Soil Analysis (Ed. Black, C.A.). Amer. Soc. Agron. Mon. 9. Madison, Wis.

Andrews, S. S., Karlen, D. L., ve Cambardella, C. A. (2004). The soil management assessment framework: a quantitative soil quality evaluation method. Soil Science Society of America Journal, 68(6), 1945-1962.

Anonim, $2019 . \quad$ https://tr.climatedata.org/asya/tuerkiye/adana/yumurtalık-847384/

Armenise, E., Redmile-Gordon, M. A., Stellacci, A. M., Ciccarese, A., ve Rubino, P. (2013). Developing a soil quality index to compare soil fitness for agricultural use under different managements in the Mediterranean environment. Soil \& Tillage Research, 130:91-98.

Bahçeci, i. (2014). Farklı drenaj yönetimlerinin Harran Ovası topraklarının tuz ve sodyum içeriğine etkileri. Harran Tarım ve Gıda Bilimleri Dergisi, 18(3), 1-12.

Bayman, S., ve Turgut, M. M. (2018). The effect of different tillage practices on the soil bacteria microflora in winter wheat cultivation. Scientific Papers. Series $A$. Agronomy, 61(2), 109-114.

Bouyoucus, G. J. (1951). A recalibration of the hydrometer method for making mechanical analysis of soils. Agronomy Journal, 43, 434-438.

Budak, M., Günal, H., Celik, I., Yıldız, H., Acir, N., ve Acar, M. (2018). Soil quality assesment of upper Tigris basin. Carpathian Journal of Earth and Environmental Sciences, 13(1), 301-316.

Bunemann, E. K., Bongiorno, G., Bai, Z., Creamer, R. E., de Deyn, G., de Goede, R., ... Brussaard, L. (2018). Soil quality - A critical review. Soil Biology and Biochemistry, 120, 105-125.

Cambardella, C. A., Moorman, T. B., Novak, J. M., Parkin, T. B., Karlen, D. L., Turco, R. F. ve Konopka, A. E. (1994). Field-scale variability soil properties in central lowa soils. Soil Science Society of America Journal, 58, 1501-1511.

Cherubin, M. R., Karlen, D. L., Franco, A. L. C., Cerri, C. E. P., Tormena, C. A., ve Cerri, C. C. (2016). A soil management assessment framework (SMAF) evaluation of brazilian sugarcane expansion on soil quality. Soil Science Society of America Journal, 80, 215-226.

Celik, i., Turgut, M. M., ve Acir, N. (2012). Crop rotation and tillage effects on selected soil Physical properties of a Typic Haploxerert in an irrigated semi-arid Mediterranean region. International Journal of Plant Production, 6(4), 457-480.

Celik, I., Barut Bereket, Z., Ortas, I., Gok, M., Demirbas, A., Tulun, Y., ve Akpinar, C. (2011). Impacts of different tillage practices on some soil microbiological properties and crop yield under semi-arid Mediterranean conditions. International Journal of Plant Production, 5(3), 237-254.

Dengiz, O., Özyazıcı, M.A., ve Sağlam, M. (2015). MultiCriteria assessment and geostatistical approach for determination of rice growing suitability sites in Gokirmak catchment. Paddy Water Environment, 13: 1-10. DOI 10.1007/s10333-013-0400-4.

Dengiz, O. (2019). Soil quality index for paddy fields based on standard scoring functions and weight allocation method. Archives of Agronomy and Soil Science. https://doi.org/10.1080/03650340.2019.1610880

Dinç, U., Sarı, M., Şenol, S., Kapur, S., Sayın, M., Derici, R., ve Ağca, N. (1995). Çukurova Bölgesi Toprakları, Çukurova Üniversitesi, Ziraat Fakültesi, Yardımcı Ders Kitabı No:26 sayfa 172.

Gugino, B. K., Abawi, G. S., Idowu, O. J., Schindelbeck, R. R., Smith, L. L., Thies, J. E., ve ... Van Es, H. M. (2009). Cornell soil health assessment training manual, Cornell University College of Agriculture and Life Sciences, Cornell University, Geneva, NY.

Karlen, D. L., Andrews, S. S., ve Doran, J. W. (2001). Soil quality: Current concepts and applications. In: Advances in Agronomy, Academic Press, Volume 74, Pages 1-40, DOi: 10.1016/S0065-2113(01)74029-1.

Karlen, D. L., Mausbach, M. J., Doran, J. W., Cline, R. G., Harris, R. F., ve Schumann, G. E. (1997). Soil quality: A concept, definition, and framework for evaluation. Soil Science Society of America Journal, 61, 4-10.

Karlen, D. L., ve Stott, D.E. (1994). A framework for evaluating physical and chemical indicators of soil quality. In Doran, J.W., Coleman, D.C., Bezdicek, D.F., and Stewart, B.A., (Eds). Defining Soil Quality for a Sustainable Environment. Soil Science Society of America pecial Publication No. 35, Soil Science Society of America, Madison, WI. p. 53-72.

Koca, Y. K. (2014). Toprak Etüdlerinde Uzman Gereksinimini Azaltacak Yöntemlerin Adana illi Örneğinde Araştırılması. Çukurova Üniversitesi, Fen Bilimleri Enstitüsü, Doktora tezi, 214 sayfa.

Koca, Y. K., ve Şenol, S. (2018). The possibilities of using stereo satellite datas on soil surveys. Yuzuncu $Y_{\imath} l$ University Journal of Agricultural Sciences, 28, 176179.

Liebig, M. A., Varvel, G., ve Doran, J. (2001). A simple performance-based index for assessing multiple agroecosystem functions. Agronomy Journal, 93, 
313-318.

Liu, J., Wu, L., Chen, D., Yu, Z., ve Wei, C. (2018). Development of a soil quality index for Camellia oleifera forestland yield under three different parent materials in Southern China. Soil \& Tillage Research, 176, 45-50.

Marschner, H. (2011). Marschner's Mineral Nutrition of Higher Plants. 3rd Edition, London: Academic Press.

Mohammad, S. N. ve Mohd M. A. (2014). Land suitability analysis for sustainable agricultural and use planning in Bulandshahr District of Uttar Pradesh. International Journal of Scientific and Research Publications, 4(3), 1-11.

Masto, R. E., Chhonkar, P. K., Singh, D., ve Patra, A. K. (2008). Alternative soil quality indices for evaluating the effect of intensive cropping, fertilisation and manuring for 31 years in the semi-arid soils of India. Environmental Monitoring and Assessment, 136,
419-435.

Saaty, R. W. (1987). The analytic hierarchy process - what it is and how it is used. Mathematical Modelling, 9(35), 161-176.

Saaty, T. L. (1980). The Analytic Hierarchy Process: Planning, Priority Setting and Resource Allocation. New York: McGraw-Hill.

Schlichting, E., ve Blume, E. (1966). Bodenkundliches Praktikum. Verlag Paul Parey, Hamburg und Berlin: Preis: Kartoniert.

U. S. Salinity Laboratory Staff (1954). Diagnosis and Improvement of Saline and Alkali Soils. Editor: Richards, L.A., USDA Agriculture Handbook. No: 60, US: Goverment Print Office.

Wymore, A. W. (1993). Model-based systems engineering: An introduction to the mathematical theory of discrete systems and to the tricotyledon theory of system design. CRC Press, Inc., Boca Raton, FL. 